James Madison University JMU Scholarly Commons

Senior Honors Projects, 2010-current

Honors College

Spring 2017

\title{
Elucidation of active sites for the reaction of ethanol on $\mathrm{TiO}_{2} / \mathrm{Au}(111)$
}

David T. Boyle

James Madison University

Follow this and additional works at: https://commons.lib.jmu.edu/honors201019

Part of the Materials Chemistry Commons

\section{Recommended Citation}

Boyle, David T., "Elucidation of active sites for the reaction of ethanol on TiO2/Au(111)" (2017). Senior Honors Projects, 2010-current. 351.

https://commons.lib.jmu.edu/honors201019/351

This Thesis is brought to you for free and open access by the Honors College at JMU Scholarly Commons. It has been accepted for inclusion in Senior Honors Projects, 2010-current by an authorized administrator of JMU Scholarly Commons. For more information, please contact dc_admin@jmu.edu. 
Elucidation of Active Sites for the Reaction of Ethanol on $\mathrm{TiO}_{2} / \mathrm{Au}(111)$

An Honors College Project Presented to

the Faculty of the Undergraduate

College of Science and Mathematics

James Madison University

by David Thomas Boyle

May 2017

Accepted by the faculty of the Department of Chemistry and Biochemistry, James Madison University, in partial fulfillment of the requirements for the Honors College.

FACULTY COMMITTEE:

HONORS COLLEGE APPROVAL:

Project Advisor: Ashleigh E. Baber, Ph.D. Assistant Professor, Chemistry
Bradley R. Newcomer, Ph.D.,

Dean, Honors College

Reader: Thomas C. Devore, Ph.D.

Professor, Chemistry

Reader: Brycelyn M. Boardman, Ph.D.

Assistant Professor, Chemistry

\section{PUBLIC PRESENTATION}

This work is accepted for presentation, in part or in full, at the Chemistry \& Biochemistry Spring

Research Symposium on March 23, 2017 \& the $253^{\text {rd }}$ meeting of the ACS on April 2, 2017. 


\section{Table of Contents}

List of Figures $\quad 3$

$\begin{array}{ll}\text { Acknowledgements } & 4\end{array}$

$\begin{array}{ll}\text { Abstract } & 5\end{array}$

$\begin{array}{ll}\text { Introduction } & 6\end{array}$

$\begin{array}{ll}\text { Methods } & 8\end{array}$

$\begin{array}{ll}\text { Results and Discussion } & 10\end{array}$

$\begin{array}{ll}\text { Conclusions } & 27\end{array}$

$\begin{array}{ll}\text { Supporting Information/Appendix } & 28\end{array}$

References 


\section{List of Figures}

Figure 1: TPD spectra of low coverages of ethanol on clean $\mathrm{Au}(111) . \quad 11$

Figure 2: TPD spectra of ethanol on clean and sputtered $\mathrm{Au}(111) . \quad 13$

Figure 3: TPD spectra of a series of ethanol coverages at saturation coverage $\quad 15$ (1.0 ML) and above on $\mathrm{Au}(111)$.

Figure 4: Zoomed in perspective of desorption features corresponding to terrace $\mathrm{Au}$ sites and Au kink sites.

Figure 5: Ex situ AFM images of $\mathrm{Au}(111)$ and $~ 0.6 \mathrm{ML} \mathrm{TiO}_{2} / \mathrm{Au}(111)$.

Figure 6: TPD spectra of a coverage-dependent study of ethanol/ $\mathrm{TiO}_{2} / \mathrm{Au}(111)$.

Figure 7: TPD spectra of ethanol desorption from clean $\mathrm{Au}(111)$ and nanoparticle $\mathrm{TiO}_{2} / \mathrm{Au}(111)$.

Figure 8: TPR spectrum of ethanol-derived products formed over $\mathrm{TiO}_{2} / \mathrm{Au}(111)$.

Figure S1: Ex situ AFM images of clean Au(111) and roughened Au(111). 28

Figure S2: Ex situ XPS of clean $\mathrm{Au}(111)$ and $0.6 \mathrm{ML} \mathrm{TiO}_{2} / \mathrm{Au}(111)$.

Figure S3: Histogram of $\mathrm{TiO}_{2}$ nanoparticle diameters. 30

Figure S4: Peak fitting of ethanol desorption from $\mathrm{TiO}_{2} / \mathrm{Au}(111) . \quad 31$ 


\section{Acknowledgments}

I first want to thank my advisor, Dr. Ashleigh Baber. She has been an exceptional role model to me as both a young person and young scientist. All of the work presented herein would not be possible without her guidance and mentorship. I also want to thank Dr. Thomas Devore and Dr. Brycelyn Boardman for discussing this project with me and agreeing to be readers for this project. Thank you to all the members of the lab including Jeremy Wilke, Vivian Lam, Daniel Schlosser, Wil Andahazy and Cameron Stopak for their help carrying out experiments. I also want to thank Dr. Barbara Reisner for facilitating my transition into Dr. Baber's research lab during the first week of my sophomore year.

I want to acknowledge the College of Science and Mathematics and the Department of Chemistry and Biochemistry for providing me with the necessary funds to participate in summer research and professional conferences. Finally, I want to thank James Madison University for providing me with a Second Century Scholarship in STEM throughout my time at JMU.

Finally, I want to thank my parents for ultimately making my education and research at JMU possible. 


\begin{abstract}
Obtaining a molecular-level understanding of the reaction of alcohols with heterogeneous model catalysts is critical for improving industrial catalytic processes, such as the production of $\mathrm{H}_{2}$ from alcohols. Gold has been shown to be an excellent oxidation catalyst once oxygen is added to it. The use of reducible oxides provides a source of oxygen on Au(111) for the reaction of ethanol, which is easily regenerated in the presence of an oxygen background. In this work, ethanol operates as a probe molecule to investigate the role of $\mathrm{Au}(111), \mathrm{TiO}_{2}$ nanoparticles, and $\mathrm{TiO}_{2} / \mathrm{Au}$ interfacial surface sites on the catalytic properties of $\mathrm{TiO}_{2} / \mathrm{Au}(111)$. Ultrahigh vacuum temperature programmed desorption (TPD) studies with ethanol/Au(111) elucidate previously unreported adsorption sites for ethanol. Ethanol molecularly adsorbs to Au terrace sites, step edges, and undercoordinated kink sites with adsorption energies of $-51.7,-55.8$, and -65.1 $\mathrm{kJ} / \mathrm{mol}$, respectively. A TPD coverage study of ethanol on $\mathrm{TiO}_{2} / \mathrm{Au}(111)$ indicates ethanol undergoes dissociative adsorption to form $\mathrm{H}^{*}(\mathrm{a})$ and $\mathrm{CH}_{3} \mathrm{CH}_{2} \mathrm{O} *(\mathrm{a})$ on the inverse model catalyst surface. The desorption temperature of low coverages of ethanol from $\mathrm{TiO}_{2} / \mathrm{Au}(111)\left(T_{\text {des }}=\sim 235\right.$ $\mathrm{K})$ is at an intermediate temperature between the desorption temperatures from bulk $\mathrm{Au}(111)$ and $\mathrm{TiO}_{2}(110)$, indicating both $\mathrm{Au}$ and $\mathrm{TiO}_{2}$ play a role in the adsorption of ethanol. Both lowtemperature adsorption and high-temperature reactions are studied and indicate that ethanolderived products — such as acetaldehyde and ethylene — desorb from $\mathrm{TiO}_{2} / \mathrm{Au}(111)$ at $\sim 500 \mathrm{~K}$.
\end{abstract}

All the work reported herein is published in the Journal of Physical Chemistry C:

Boyle, D. T.; Wilke, J. A.; Palomino, R. M.; Lam, V. H.; Schlosser, D. A.; Andahazy, W. J.;

Stopak, C. Z.; Stacchiola, D. J.; Rodriguez, J. A.; Baber, A. E. J. Phys. Chem. C 2017, Article ASAP. DOI: $\underline{10.1021 / a c s . j p c c .6 b 11764}$ 


\section{Introduction}

Heterogeneous $\mathrm{Au} / \mathrm{TiO}_{2}$ model catalysts have been extensively studied due to their remarkable catalytic activity toward the water-gas shift reaction, ${ }^{1-4}$ production of $\mathrm{H}_{2}$ from alcohols, ${ }^{5-8}$ oxidation of $\mathrm{CO}$ to $\mathrm{CO}_{2},{ }^{4,9-11}$ and several other applications ${ }^{1}$. It has been proposed that the interface between $\mathrm{Au}$ nanoparticles and $\mathrm{TiO}_{2}$ is the catalytically active site of $\mathrm{Au} / \mathrm{TiO} 2$ heterogeneous catalysts for the conversion of small alcohols to their respective carbonyls and alkenes, water-gas shift reaction, and $\mathrm{H}_{2}$ dissociation. ${ }^{4,9,10,12,13}$ In order to determine the role of distinct $\mathrm{Au}, \mathrm{TiO}_{2}$, and $\mathrm{Au} / \mathrm{TiO}_{2}$ interfacial sites in $\mathrm{Au} / \mathrm{TiO}_{2}$ heterogeneous catalysts, inverse model catalysts have become a material of interest. Using inverse model catalysts in which $\mathrm{TiO}_{2}$ nanoparticles are deposited onto a $\mathrm{Au}(111)$ substrate allows for the use of surface science techniques to investigate the role of distinct surface sites on the overall reactivity of the $\mathrm{TiO}_{2} / \mathrm{Au}(111)$ catalyst.

Ethanol is the simplest molecule containing $\mathrm{C}-\mathrm{H}, \mathrm{C}-\mathrm{O}, \mathrm{C}-\mathrm{C}$, and $\mathrm{O}-\mathrm{H}$ bonds, which makes it an excellent probe molecule to elucidate active sites on $\mathrm{TiO}_{2} / \mathrm{Au}(111)$ inverse model catalyst surfaces. Additionally, ethanol is particularly interesting to the catalytic community, as it is used as an alternative fuel and chemical feedstock for important industrial reactions like the production of $\mathrm{H}_{2}$ and acetic acid. ${ }^{14}$ Ethanol has been utilized to probe the catalytic activity of several $\mathrm{Au} / \mathrm{TiO}_{2}$-based surfaces including: $\mathrm{O} / \mathrm{Au}(111),{ }^{15,16} \mathrm{TiO}_{2}(110),{ }^{17-20}$ and $\mathrm{Au} / \mathrm{TiO}_{2}(110)^{1}$. It is well understood that ethanol undergoes molecular adsorption on clean $\mathrm{Au}(111)$ and dissociative adsorption on $\mathrm{O} / \mathrm{Au}(111)$ and bulk $\mathrm{TiO}_{2}(110)$ to form ethoxy and hydroxyl adsorbates. ${ }^{15-20}$ The reaction of ethanol on bulk rutile- $\mathrm{TiO}_{2}(110)$ single crystals showed that both acetaldehyde and ethylene were produced at $\sim 620 \mathrm{~K} .{ }^{20}$ The formation of a carbonyl group versus an alkene was dependent on the number of defects in the crystal surface, as an increased concentration of oxygen vacancies promoted the formation of ethylene. ${ }^{20}$ 
Interestingly, low temperature ethanol adsorption and ethanol chemistry on $\mathrm{TiO}_{2} / \mathrm{Au}(111)$ surfaces has not yet been reported. Studies with other simple alcohols methanol ${ }^{21}$ and 2propanol $^{22}$ on $\mathrm{TiO}_{2} / \mathrm{Au}(111)$ inverse model catalysts showed that the alcohols underwent an elimination or oxidation reaction depending on the method of surface preparation. Both studies proposed that the formation of the oxidized products - formaldehyde and acetone - were the result of excess oxygen on the surface. The formation of elimination products - methane and propene-were the result of undercoordinated $\mathrm{Ti}$ cations within the $\mathrm{TiO}_{2}$ nanoparticles supported on $\mathrm{Au}(111)$. While $\mathrm{TiO}_{2} / \mathrm{Au}(111)$ showed catalytically valuable chemistry toward methanol and 2-propanol, the role of distinct $\mathrm{Au}, \mathrm{TiO}_{2}$, and $\mathrm{Au} / \mathrm{TiO}_{2}$ interfacial sites on the overall reactivity of the surface was not reported.

In this work, a comprehensive study of low temperature ethanol adsorption and chemistry over $\mathrm{Au}(111)$ and $\mathrm{TiO}_{2} / \mathrm{Au}(111)$ is reported across a wide temperature range to determine the catalytically active sites of $\mathrm{TiO}_{2} / \mathrm{Au}(111)$. The role of distinct $\mathrm{Au}, \mathrm{TiO}_{2}$, and $\mathrm{Au} / \mathrm{TiO}_{2}$ interfacial sites is investigated through the use of ultrahigh vacuum temperature-programmed desorption (UHV-TPD), atomic force microscopy (AFM), and X-ray photoelectron spectroscopy (XPS). Low-temperature desorption relays information about binding energies and adsorption sites of ethanol to $\mathrm{Au}(111)$ and $\mathrm{TiO}_{2} / \mathrm{Au}(111)$, and high-temperature desorption is used to investigate the chemistry of the ethanol over the $\mathrm{TiO}_{2} / \mathrm{Au}(111)$ surface. The results shown here demonstrate the $\mathrm{TiO}_{2}-\mathrm{Au}$ interface as the active catalytic site on inverse model catalysts for the reaction of ethanol. 


\section{Methods}

Experiments were performed in a UHV-TPD chamber. The UHV chamber is pumped by turbo and titanium sublimation pumps and maintained a base pressure of $\sim 5 \times 10^{-10}$ Torr during experiments. The chamber contains a quadrupole mass spectrometer (Hiden HAL3F-RC) for TPD and residual gas analysis. The heating rate for TPD experiments was $1.05 \mathrm{~K} / \mathrm{s}$. Collimated high precision leak valves were used for controlling gas doses into the chamber.

$\mathrm{A} \mathrm{Au}(111)$ single crystal (Princeton Scientific) was mounted on a sample holder and held vertically by tungsten wires (Goodfellow, 99.95\%, $0.25 \mathrm{~mm}$ diameter) between two copper blocks in the center of the chamber, which allowed the sample to be resistively heated and cooled with liquid nitrogen. Temperature measurements were recorded with a k-type thermocouple that was directly attached to a hole in the side of the $\mathrm{Au}(111)$ crystal. The $\mathrm{Au}(111)$ surface was prepared via cycles of $1 \mathrm{keV} \mathrm{Ar}^{+}$sputtering and annealing in UHV at $\sim 850 \mathrm{~K}$. The cleanliness of the surface was determined via Auger electron spectroscopy (AES), TPD of probe molecules, ex situ AFM, and XPS. $\mathrm{TiO}_{2}$ was deposited on the $\mathrm{Au}(111)$ single crystal by the physical vapor deposition of $\mathrm{Ti}$ at an oxygen background pressure of $2 \times 10^{-7}$ Torr at room temperature, and then annealed in $\mathrm{O}_{2}$ to $600 \mathrm{~K}$. For the physical vapor deposition, a homemade Ti filament made with Ti wire (0.125 mm diameter, $99.6 \%$, Goodfellow) was used. Monolayer coverages of $\mathrm{TiO}_{2}$ were controlled by monitoring the power input and deposition time and determined by ex situ AFM and XPS. Ex situ AFM images were recorded by a Digital Instruments MultiMode AFM in tapping mode under ambient conditions. The saturation coverage of ethanol is defined as 1 monolayer (ML) and was calibrated using TPD. XPS was performed on a PerkinElmer 5400 X-ray Photoelectron Spectrometer equipped with a monochromatized $\mathrm{Mg}(\mathrm{K} \alpha)$ radiation source $(1253.6 \mathrm{eV})$ and a position sensitive, multichannel 
plate detector. Measurements were taken at a pressure of $\sim 10^{-7}$ mbar and with a takeoff angle of $15^{\circ}$ with respect to the surface normal. Binding energies are referenced to $\mathrm{Au} 4 \mathrm{f}_{7 / 2}$ at $84.0 \mathrm{eV}$. 


\section{Results and Discussion}

Prior to studying the low-temperature adsorption and chemistry of ethanol on $\mathrm{TiO}_{2} / \mathrm{Au}(111)$, a comprehensive understanding of ethanol adsorption on clean $\mathrm{Au}(111)$ is critical for interpreting the role of each individual material on the reactivity of the composite inverse model catalyst. In this work, the coverage-dependent TPD studies of ethanol/Au(111) elucidate previously unreported adsorption sites for ethanol on $\mathrm{Au}(111)$. Figure 1 shows TPD results from ethanol coverages below $0.20 \mathrm{ML}$, where a $\mathrm{m} / \mathrm{z}$ ratio of 31 was followed, as it is the most intense fragment for ethanol. At ethanol coverages below 0.20 ML, the TPD spectra show two desorption features with desorption temperatures of $T_{d e s}=172$ and $185 \mathrm{~K}$. The desorption feature at $T_{d e s}=172 \mathrm{~K}$ is related to ethanol desorbing from the $\mathrm{Au}(111)$ terrace, and is in agreement with previous work on ethanol/Au(111). ${ }^{15}$ The consistency in $T_{\text {des }}=172 \mathrm{~K}$ as the monolayer coverage of ethanol increases indicates first-order kinetics of desorption, which confirms that ethanol adsorbs and desorbs molecularly from the $\mathrm{Au}(111)$ terrace. Interestingly, TPD spectra of low ethanol coverages on $\mathrm{Au}(111)$ show a desorption feature at $T_{d e s}=185 \mathrm{~K}$. At ethanol coverages as low as $0.01 \mathrm{ML}$, the desorption feature at $T_{d e s}=185 \mathrm{~K}$ predominates with a slight low-temperature shoulder, indicating that the adsorption site corresponding to $T_{d e s}=185 \mathrm{~K}$ is preferentially populated prior to $\mathrm{Au}(111)$ terrace sites. Upon increasing the coverage of ethanol above 0.01 ML, the desorption feature at $T_{d e s}=185 \mathrm{~K}$ saturates, and the desorption feature at $T_{d e s}=172 \mathrm{~K}$, representing ethanol desorption from $\mathrm{Au}(111)$ terrace sites, continues to grow in intensity up to a coverage of $0.20 \mathrm{ML}$ of ethanol. 


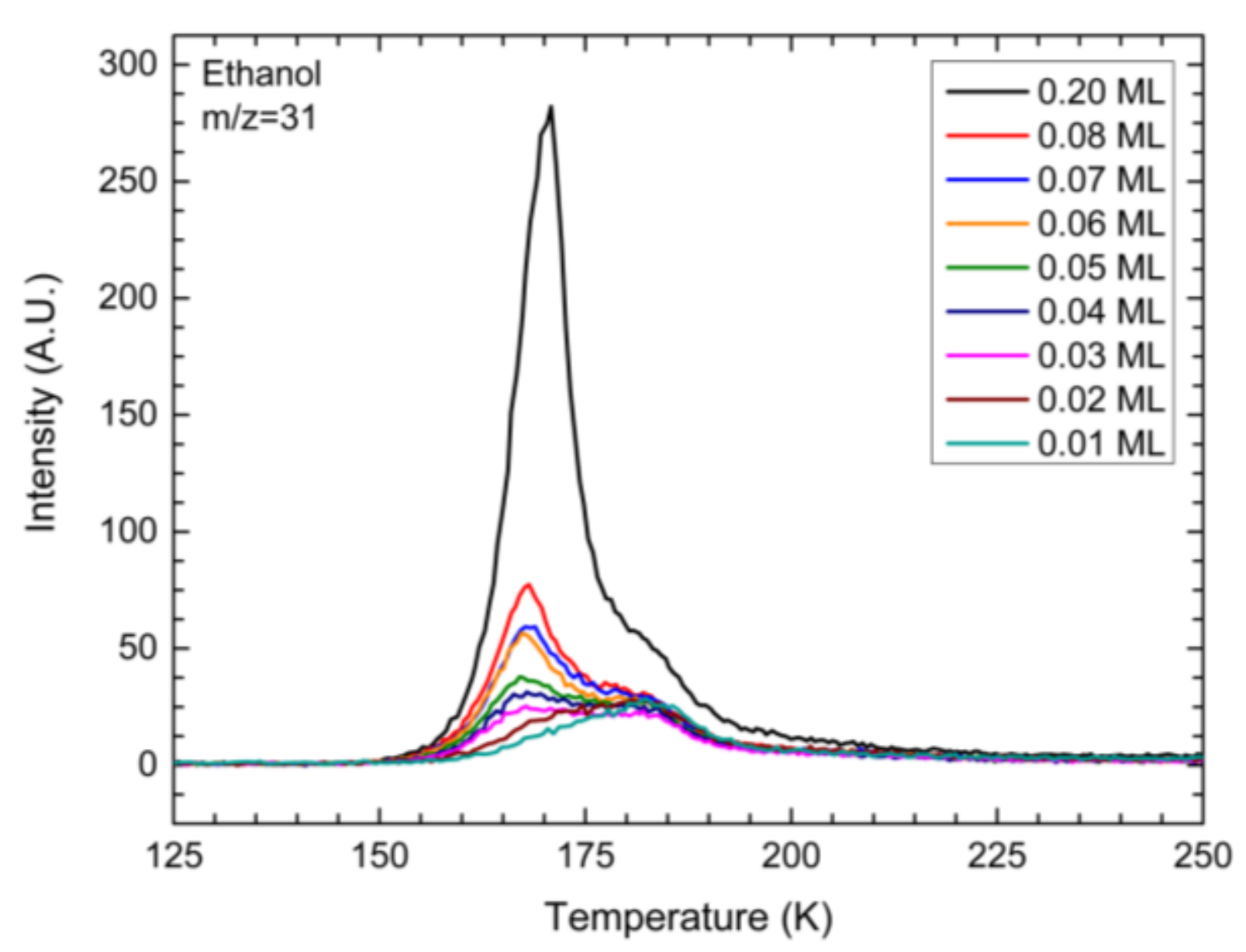

Figure 1. TPD spectra of low coverages of ethanol $(\mathrm{m} / \mathrm{z}=31)$ from $\mathrm{Au}(111)$. The peak at $T_{d e s}=172 \mathrm{~K}$ represents submonolayer coverages of the molecular desorption of ethanol from $\mathrm{Au}$ terraces, and the peak at $T_{\text {des }}=185 \mathrm{~K}$ is assigned to the molecular desorption of ethanol from step edges.

The observation of two distinct desorption features in the TPD spectra indicates that there are two distinct adsorption sites for ethanol on $\mathrm{Au}(111)$. Previous studies of $\mathrm{CO} / \mathrm{Au}(111)$ demonstrated that a sputtered $\mathrm{Au}(111)$ surface enhanced the adsorption of $\mathrm{CO}$ by exposing more undercoordinated $\mathrm{Au}$ step edges and kink sites. ${ }^{23-28} \mathrm{CO}$ had stronger binding energies to undercoordinated Au sites, which resulted in a higher $T_{\text {des }}{ }^{27}$ In order to investigate the desorption 
of ethanol from undercoordinated Au sites, the clean $\mathrm{Au}(111)$ surface was sputtered by bombarding the surface with $1 \mathrm{keV} \mathrm{Ar}^{+}$ions at $300 \mathrm{~K}$. The morphology of a sputtered $\mathrm{Au}(111)$ single crystal was imaged using ex situ AFM, which showed the presence of large pits with roughened step edges (Figure S1). The sputtered surface results in an ethanol TPD spectrum with noticeable differences from the clean $\mathrm{Au}(111)$ surface (Figure 2). Upon sputtering the surface, the desorption feature at $T_{d e s}=185 \mathrm{~K}$ grows in intensity, whereas the desorption feature at $T_{d e s}=172 \mathrm{~K}$ decreases in intensity. Consequently, the peak at $T_{d e s}=185 \mathrm{~K}$ is assigned to the desorption of ethanol from undercoordinated Au sites. Annealing Au(111) to $400 \mathrm{~K}$ and above decreases the number of undercoordinated Au sites by smoothing the sputtered surface. ${ }^{27,29}$ After annealing the sputtered $\mathrm{Au}(111)$ surface to $400 \mathrm{~K}$, the desorption feature at $T_{\text {des }}=172 \mathrm{~K}$ increases in intensity, while the desorption feature for undercoordinated Au sites $\left(T_{\text {des }}=185 \mathrm{~K}\right)$ decreases, indicating that the $400 \mathrm{~K}$ anneal results in a smoother $\mathrm{Au}(111)$ surface. While sputtering the surface results in an increased number of undercoordinated sites of both step edges and kink sites, ${ }^{23,25-28}$ the peak at $185 \mathrm{~K}$ is assigned to Au step edges, as the concentration of step edges is expected to be much greater than that of kink sites. 


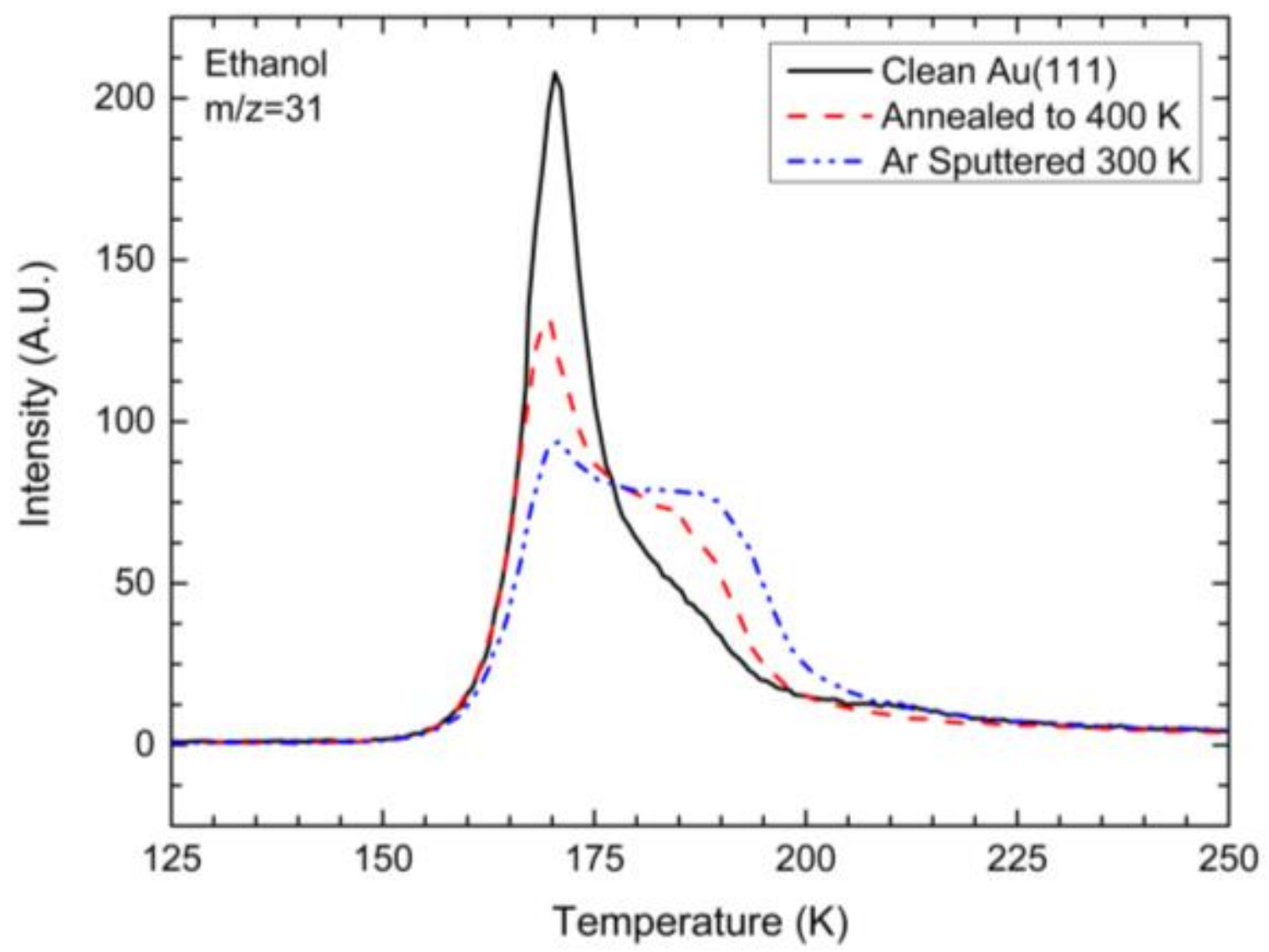

Figure 2. TPD spectra of ethanol on clean and sputtered $\mathrm{Au}(111)$ surfaces $(\mathrm{m} / \mathrm{z}=31)$. Annealing the surface to $400 \mathrm{~K}$ partially smooths the surface, which results in a decrease in ethanol desorption at $T_{\mathrm{des}}=185 \mathrm{~K}$ (step edges) and an increase in ethanol desorption from the terraces at $T_{\text {des }}=172 \mathrm{~K}$.

The adsorption energies of ethanol on $\mathrm{Au}(111)$ terrace sites and Au step edges can be calculated using the Redhead approximation for first-order desorption

$$
E_{\text {des }}=R T_{\text {des }}\left[\operatorname { l n } \left(T_{\text {des }} / \quad\right.\right. \text { ) 3.46] }
$$

where $\beta$ is the heating rate of $1.05 \pm 0.07 \mathrm{~K} / \mathrm{s}$ and $v$ is the pre-exponential factor. A preexponential factor of $10^{15}$ was used to calculate adsorption energies of $-0.54 \mathrm{eV}(-51.7 \mathrm{~kJ} / \mathrm{mol})$ and $-0.58 \mathrm{eV}(-55.8 \mathrm{~kJ} / \mathrm{mol})$ for ethanol adsorbed to terrace $\mathrm{Au}(111)$ sites and Au step edges, 
respectively. The calculated adsorption energy on $\mathrm{Au}(111)$ terraces of $-0.54 \mathrm{eV}$ is in agreement with previous DFT studies, which resulted in an adsorption energy of $-0.536 \mathrm{eV} .{ }^{30}$ The same DFT calculations, which included a van der Waals correction, predict that ethanol adsorbs to the $\mathrm{Au}(111)$ surface with the $\mathrm{C}-\mathrm{C}$ bond parallel to the surface. ${ }^{30}$

To further investigate the desorption of ethanol from Au(111), TPD studies of ethanol coverages above 1.0 ML were performed on clean $\mathrm{Au}(111)$ (Figure 3). As the coverage of ethanol increases, the Au terrace peak $\left(T_{d e s}=172 \mathrm{~K}\right)$ increases in intensity and saturates at $1.0 \mathrm{ML}$ of ethanol. It is important to note that the peak previously observed for step edges $(185 \mathrm{~K})$ is now obscured by the terrace desorption peak. Additionally, upon increasing the ethanol coverage above 1.0 ML, low-temperature peaks corresponding to multilayered ethanol appear $\left(T_{\text {des }}<155\right.$ $\mathrm{K})$. The desorption feature corresponding to multilayered ethanol increases to a maximum desorption temperature of $T_{\text {des }}=150 \mathrm{~K}$, until a low-temperature shoulder appears at $T_{d e s}=145 \mathrm{~K}$ above 1.8 ML. The desorption of multilayered ethanol at $T_{d e s}=150 \mathrm{~K}$ and ethanol from $\mathrm{Au}(111)$ terraces at $T_{d e s}=172 \mathrm{~K}$ is consistent with previous reports. ${ }^{15}$ The desorption peaks at $T_{d e s}=150$ and $T_{\text {des }}=145 \mathrm{~K}$ are assigned as multilayers of ethanol. Previous work with methanol exhibited more than one multilayer peak on $\mathrm{Au}(111),{ }^{31} \mathrm{Ag}(111),{ }^{32}$ and $\mathrm{Pt}(111),{ }^{33}$ which were labeled as amorphous and crystalline phases due to the early work of Ehlers using UV photoemission and IR reflection to differentiate between multilayer structures. ${ }^{33}$ However, ethanol multilayer studies on highly oriented pyrolytic graphite $(\mathrm{HOPG})$ resulted in two desorption peaks $\left(T_{\text {des }}=145 \mathrm{~K}\right.$ and $T_{\text {des }}=142 \mathrm{~K}$ ), labeled as a bilayer and multilayer of ethanol, respectively. ${ }^{34}$ We cannot rule out one assignment over another in this case to differentiate the peaks; therefore, we label desorption peaks below $T_{\text {des }}=155 \mathrm{~K}$ as multilayers of ethanol. 


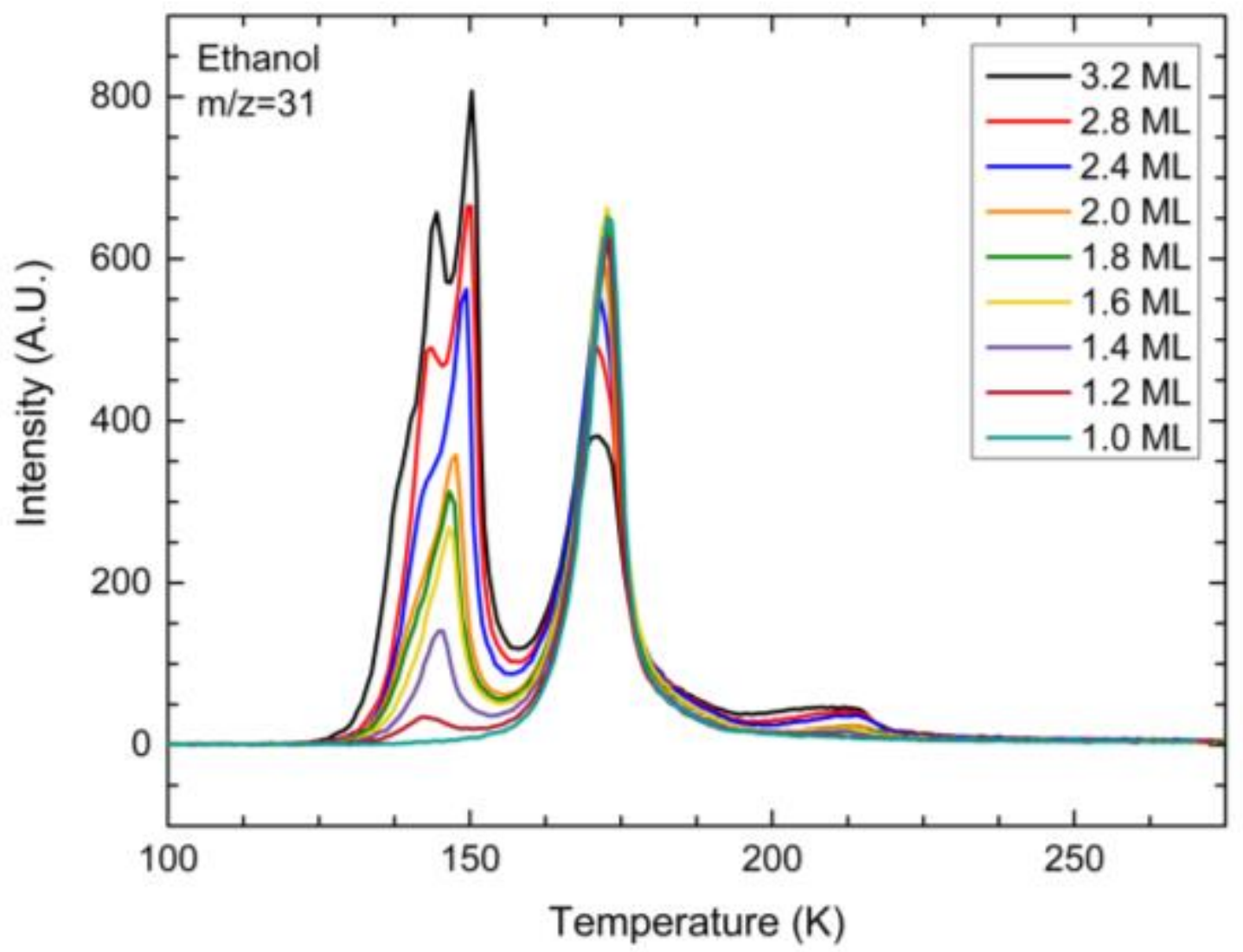

Figure 3. TPD spectra of a series of ethanol coverages $(\mathrm{m} / \mathrm{z}=31)$ at saturation coverage $(1.0$ ML) and above on $\mathrm{Au}(111)$. Desorption peaks for ethanol from multilayers $\left(T_{\text {des }}<155 \mathrm{~K}\right)$, $\mathrm{Au}$ terrace sites $\left(T_{d e s}=172 \mathrm{~K}\right)$, and undercoordinated Au kinks $\left(T_{d e s}=215 \mathrm{~K}\right)$ are present.

In addition to desorption peaks for multilayers of ethanol and ethanol adsorbed to $\mathrm{Au}(111)$ terraces, a small peak at $T_{\text {des }}=215 \mathrm{~K}$ appears with coverages of ethanol above $1 \mathrm{ML}$, as seen in Figures 3 and 4. The adsorption energy for ethanol desorbing at $215 \mathrm{~K}$, calculated using the Redhead approximation described above, is $-0.67 \mathrm{eV}(-65.1 \mathrm{~kJ} / \mathrm{mol})$. The difference in adsorption energy between Au step edges and the higher temperature desorption peak ( $T_{d e s}=215$ $\mathrm{K})$ is $-9.3 \mathrm{~kJ} / \mathrm{mol}(-0.096 \mathrm{eV})$, which is in excellent agreement with the calculated difference in adsorption energy between step edges and kink sites on $\mathrm{Au}(111)$ for $\mathrm{CO} .{ }^{27}$ Therefore, the 
desorption peak at $T_{d e s}=215 \mathrm{~K}$ is labeled as ethanol desorption from undercoordinated kink sites on $\mathrm{Au}(111)$ step edges.

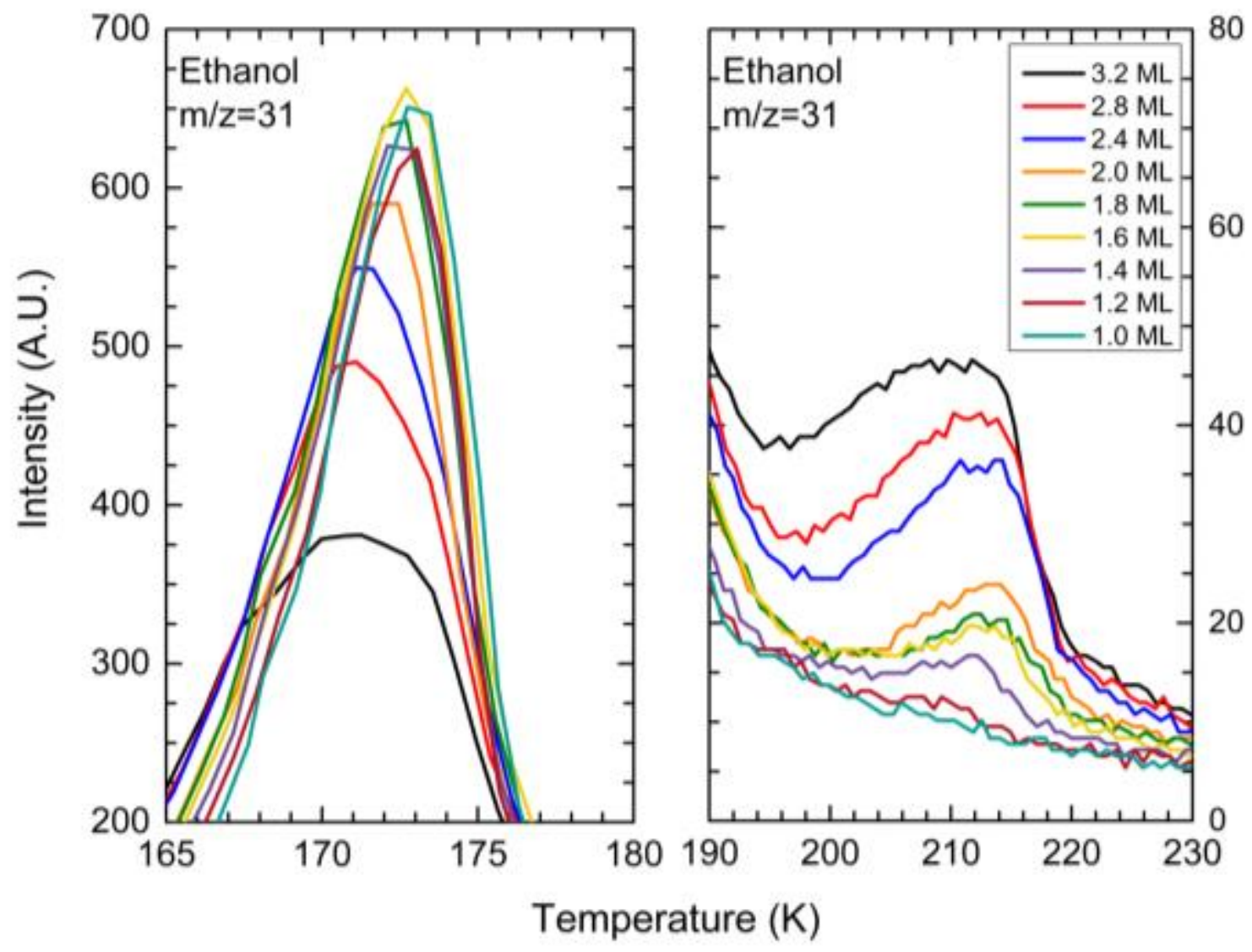

Figure 4. $\mathrm{TPD}, \mathrm{m} / \mathrm{z}=31$. Zoomed in perspective of desorption features corresponding to terrace Au sites $(172 \mathrm{~K})$ and Au kink sites $(215 \mathrm{~K})$. At ethanol coverages $>1 \mathrm{ML}$, desorption from kink sites increases and desorption from terrace sites decreases.

It is expected that undercoordinated Au sites, including step edges and kinks, would act as preferential binding sites due to their increased adsorption energy and desorption temperature compared to terrace Au sites. Interestingly, Figures 3 and 4 show an opposite trend for the population of kink sites $\left(T_{d e s}=215 \mathrm{~K}\right)$ and terrace sites $\left(T_{d e s}=172 \mathrm{~K}\right)$ as the coverage of ethanol sequentially increases. At an ethanol coverage of $1.0 \mathrm{ML}$, the only observed desorption peak is 
$172 \mathrm{~K}$. As the coverage of ethanol increases, the desorption peak at $172 \mathrm{~K}$ decreases in intensity and shifts to lower temperatures while the kink site desorption peak appears $\left(T_{\text {des }}=215 \mathrm{~K}\right)$ and continually increases (Figure 4). We hypothesize that the shift to lower temperatures of the 172 $\mathrm{K}$ desorption peak arises from the depletion of step edge desorption sites ( $\left.T_{d e s}=185 \mathrm{~K}\right)$ to form kink desorption sites. These results indicate that the presence of high coverages of ethanol roughen $\mathrm{Au}(111)$ step edges below room temperature, increasing the concentration of undercoordinated kink sites $\left(T_{d e s}=215 \mathrm{~K}\right)$. In a separate set of experiments, the coverage of ethanol was increased to $>1$ ML to produce the kink site desorption feature. Subsequently, a 1 ML ethanol dose was exposed to the surface, and the kink site desorption peak was not observed, indicating that the higher coverages of ethanol lead to the roughening of Au(111) step edges. While future studies will be required to understand the mechanism behind the formation of kinks, it is speculated that the interaction between ethanol molecules and surface Au atoms will decrease the $\mathrm{Au}-\mathrm{Au}$ bond energy, which would thereby decrease the barrier for Au diffusion. While we do not suspect the interaction between ethanol and Au is strong enough to lift the herringbone reconstruction, it is plausible that Au step edge atoms, which exhibit mobility at room temperature on clean $\mathrm{Au}(111)$, will have an enhanced mobility in the presence of ethanol, resulting in the rearrangement of step edge atoms to form kinks. Furthermore, the high coverage of ethanol required to visualize the kink site desorption feature indicates that intermolecular repulsion of ethanol molecules may also play a role in the destabilization of $\mathrm{Au}-\mathrm{Au}$ bonds. It was previously reported that intermolecular repulsion influenced the molecular packing of methanol on $\mathrm{Au}(111)$ even at submonolayer coverages. ${ }^{35}$

The rearrangement and restructuring of Au surface atoms has been observed at low pressures and temperatures after exposing small molecules to $\mathrm{Au}(111) \cdot{ }^{36-38} \mathrm{It}$ is expected that 
ethanol roughens the surface of reducible oxides. However, the oxide is reduced by ethanol via a reaction with the lattice oxygen and acidic hydrogens from ethanol to form hydroxyl groups, which recombine to form water and leave oxygen vacancies in the surface. ${ }^{39-41}$ The TPD spectra in Figures 3 and 4 therefore demonstrate the first reported roughening of the $\mathrm{Au}(111)$ step edges by ethanol at low temperatures. Future imaging studies will allow us to investigate the morphology of the $\mathrm{Au}(111)$ before, during, and after the desorption of ethanol, to investigate the reversibility of the kink formation. Additionally, imaging studies will be conducted to visualize the change in surface morphology due to ethanol adsorption at high coverages, as well as to identify a mechanism for atomic rearrangement at the step edges.

The elucidation of ethanol adsorption and desorption from distinct $\mathrm{Au}(111)$ surface sites allows for the subsequent study of low-temperature ethanol adsorption on the $\mathrm{TiO}_{2} / \mathrm{Au}(111)$ inverse model catalyst. Several preparations of $\mathrm{Au}(111)$-supported $\mathrm{TiO}_{2}$ nanoparticles are reported in the literature. ${ }^{42-46}$ For the experiments reported herein, $\mathrm{TiO}_{2}$ nanoparticles were deposited onto $\mathrm{Au}(111)$ via physical vapor deposition in an $\mathrm{O}_{2}$ background $\left(2 \times 10^{-7}\right.$ torr) at $300 \mathrm{~K}$ and annealed to $600 \mathrm{~K}$ in $\mathrm{O}_{2}$ prior to experiments. Ex situ AFM and ex situ XPS confirmed the successful deposition of $\mathrm{TiO}_{2}$ nanoparticles on the $\mathrm{Au}(111)$ surface as compared to clean $\mathrm{Au}(111)$ (Figure 5, S2). Figure 5A shows an ex situ AFM image of the Au(111) surface prior to the deposition of $\mathrm{TiO}_{2}$ nanoparticles, with Au step edges running diagonally across the image. Figures 5B and 5C show $\mathrm{TiO}_{2}$ nanoparticles well-dispersed across the Au terrace and step edges. Analysis of the XPS data and the $\mathrm{Au} 4 \mathrm{f}$ peak attenuation confirmed a $\mathrm{TiO}_{2}$ coverage of $\sim 0.6 \mathrm{ML}$ on the $\mathrm{Au}(111)$ surface. The average diameter of the $\mathrm{TiO}_{2}$ nanoparticles is $10.1 \pm 2.2 \mathrm{~nm}$, and a particle distribution histogram is shown in Figure S3. 


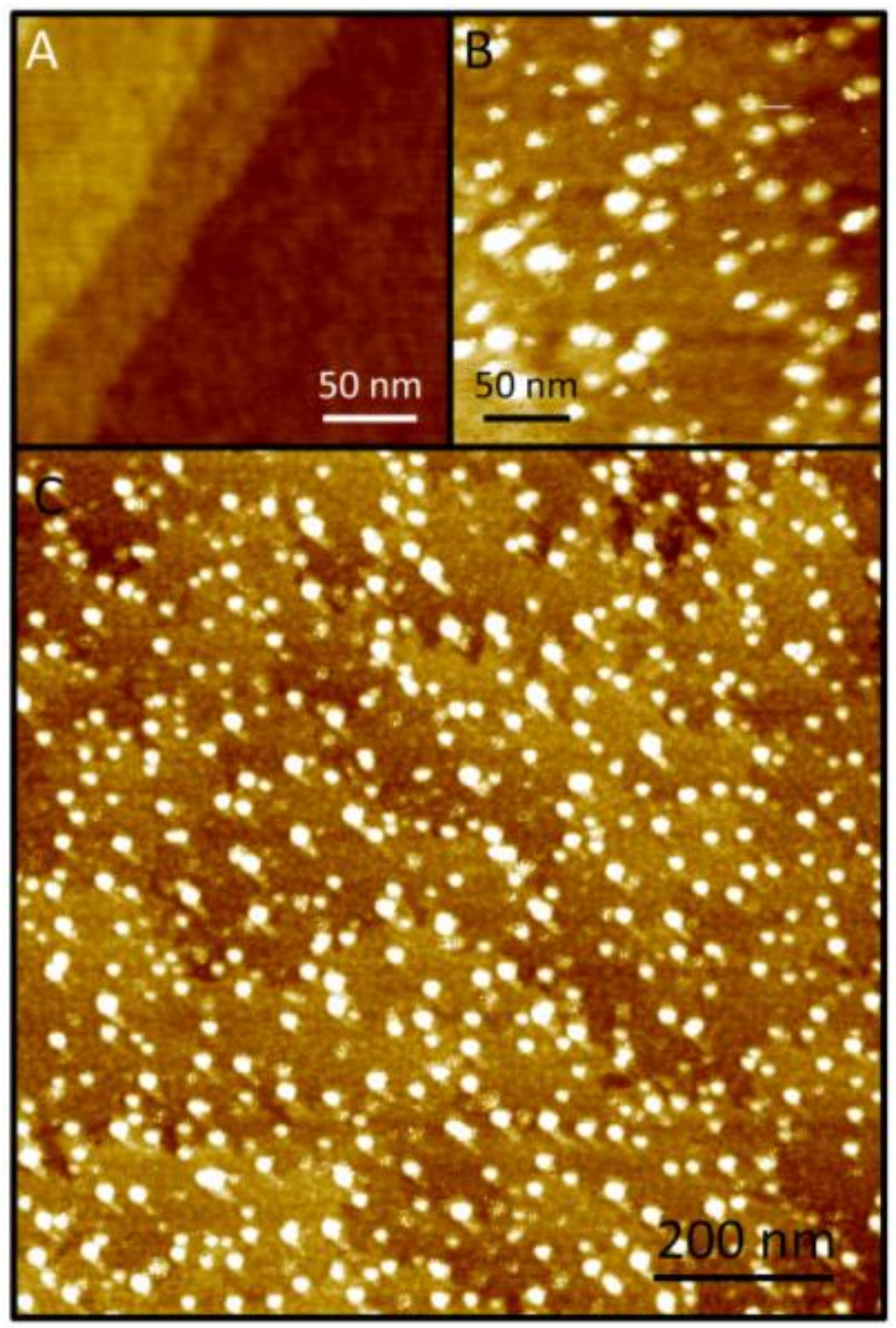

Figure 5. Ex situ AFM images of (A) $\mathrm{Au}(111)$ and $(\mathrm{B}, \mathrm{C}) \sim 0.6 \mathrm{ML} \mathrm{TiO}_{2} / \mathrm{Au}(111) . \mathrm{TiO}_{2}$ nanoparticles are highly dispersed across the $\mathrm{Au}(111)$ surface, residing on $\mathrm{Au}$ terraces and step edges.

TPD experiments of ethanol on $\mathrm{TiO}_{2} / \mathrm{Au}(111)$ showed significantly different results from those of the clean $\mathrm{Au}(111)$ surface. A coverage dependent study of ethanol on $\sim 0.7 \mathrm{ML}$ $\mathrm{TiO}_{2} / \mathrm{Au}(111)$ indicated several differences from clean $\mathrm{Au}(111) \mathrm{TPD}$ spectra (Figure 6). First, 
the $T_{\text {des }}$ of ethanol from the $\mathrm{TiO}_{2} / \mathrm{Au}(111)$ surface trends toward lower $T_{d e s}$ with increasing coverages of ethanol. Ethanol desorption from the $\mathrm{TiO}_{2} / \mathrm{Au}(111)$ surface is $T_{\text {des }}=\sim 235 \mathrm{~K}$ after only $0.3 \mathrm{~L}$ of ethanol exposure, whereas ethanol desorbs from the same $\mathrm{TiO}_{2} / \mathrm{Au}(111)$ surface at $T_{\text {des }}=\sim 195 \mathrm{~K}$ after $2.0 \mathrm{~L}$ of ethanol exposure. This trend suggests that ethanol undergoes dissociative adsorption on the surface into an adsorbed $\mathrm{H}$ and ethoxy group. The dissociative adsorption of ethanol was expected on the $\mathrm{TiO}_{2} / \mathrm{Au}(111)$ surface as previous work with aliphatic alcohols on bulk $\mathrm{TiO}_{2}(110)$ showed that ethanol dissociates into $\mathrm{H}$ and ethoxy on the surface. ${ }^{15-}$ 20

$$
\mathrm{CH}_{3} \mathrm{CH}_{2} \mathrm{OH}(\mathrm{g}) \rightarrow \mathrm{H}^{*}(\mathrm{a})+\mathrm{CH}_{3} \mathrm{CH}_{2} \mathrm{O} *(\mathrm{a})
$$

The dissociative adsorption of ethanol on $\mathrm{TiO}_{2} / \mathrm{Au}(111)$ indicates the potential for the addition of other reactant molecules to react with the activated $\mathrm{H}$ and ethoxy species on the surface. 


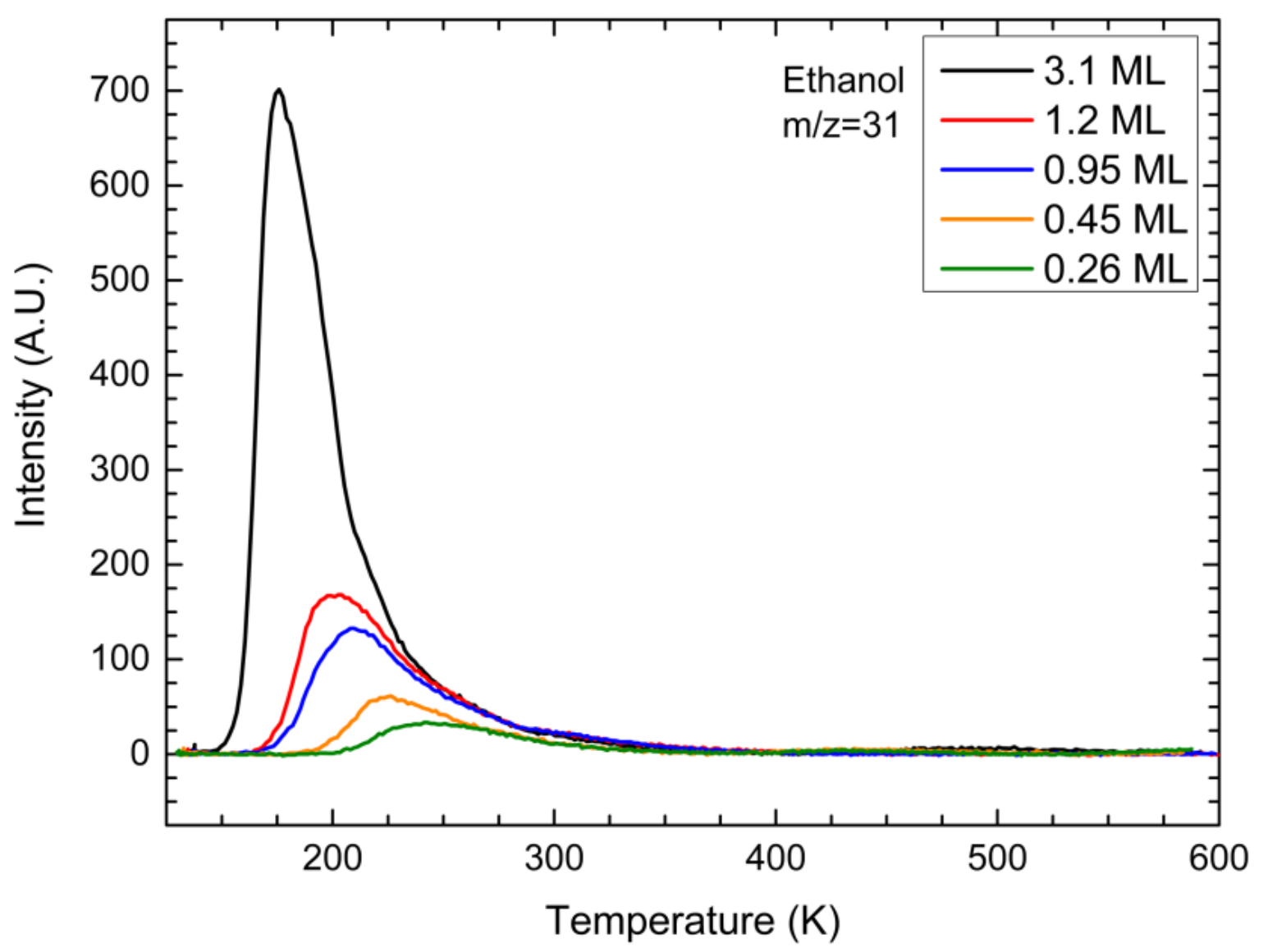

Figure 6. Coverage-dependent study of ethanol/ $/ \mathrm{TiO}_{2} / \mathrm{Au}(111) \mathrm{TPD}, \mathrm{m} / \mathrm{z}=31$. The trend in TPD spectra indicates dissociative adsorption of ethanol to $\mathrm{H}$ and ethoxy species.

The $T_{\text {des }}=\sim 235 \mathrm{~K}$ of ethanol from $\mathrm{TiO}_{2} / \mathrm{Au}(111)$ is at an intermediate temperature between those of ethanol desorption from clean $\mathrm{Au}(111)\left(172 \mathrm{~K}\right.$, Figure 3) and bulk $\mathrm{TiO}_{2}(110)$ at $300-400 \mathrm{~K} \cdot{ }^{17-20,47}$ The intermediate $T_{\text {des }}$ of ethanol from the $\mathrm{TiO}_{2} / \mathrm{Au}(111)$ surface indicates that both $\mathrm{Au}$ and $\mathrm{TiO}_{2}$ sites may contribute to the adsorption of ethanol. As the size of $\mathrm{TiO}_{2}$ decreases from bulk to nanoparticles, the number of undercoordinated atoms increases as the surface area increases, and it is expected that the desorption temperature at the undercoordinated atoms of $\mathrm{TiO}_{2}$ would be higher than that of bulk $\mathrm{TiO}_{2}$. Instead, in Figure 6, the desorption temperature related to $\mathrm{TiO}_{2}$ sites is lower than that of bulk $\mathrm{TiO}_{2}$, indicating that the ethanol adsorbs to 
interfacial sites between the $\mathrm{TiO}_{2}$ and $\mathrm{Au}$. Previous work with ethanol/CeO $/ \mathrm{Au}(111)$ proposed that the oxide/metal interface played a strong role in the catalytic activity of the material toward ethanol using XPS. ${ }^{41}$ The intermediate $T_{\text {des }}$ of ethanol from $\mathrm{TiO}_{2} / \mathrm{Au}(111)$ suggests that the interface between the $\mathrm{TiO}_{2}$ nanoparticles and the $\mathrm{Au}(111)$ substrate plays a role in the conversion of ethanol to ethoxy.

The TPD spectra of higher coverages of ethanol on $\mathrm{TiO}_{2} / \mathrm{Au}(111)$ indicate that the presence of $\mathrm{TiO}_{2}$ increases the total adsorption of ethanol (Figure 7). Ethanol desorption from clean $\mathrm{Au}(111)$ has a sharp desorption peak in the TPD spectrum that occurs at $T_{d e s}=172 \mathrm{~K}$. Interestingly, the presence of $\mathrm{TiO}_{2}$ nanoparticles results in a broad higher temperature peak centered around $T_{\text {des }}=\sim 190 \mathrm{~K}$ with a long high temperature tail. We hypothesize that the increase in total adsorbed ethanol which is demonstrated by increased area and broadening of the desorption peak, could be the result of several factors: (1) The presence of $\mathrm{TiO}_{2}$ could increase the total number of adsorption sites on the surface. Figure $5 \mathrm{C}$ shows that the $\mathrm{Au}(111)$ substrate has several step edges across the surface and $\mathrm{TiO}_{2}$ nanoparticles could pin the step edges during annealing cycles. $\mathrm{TiO}_{2}$ pins the Au step edges and results in a roughened surface with an increased number of ethanol adsorption sites on $\mathrm{Au}$ in addition to the increased number of adsorption sites on $\mathrm{TiO}_{2}$ nanoparticles. Figure $\mathrm{S} 4$ shows the peak fitting for the ethanol/ $\mathrm{TiO}_{2} / \mathrm{Au}(111)$ spectrum in Figure 7 . The peak fitting suggests that the low-temperature desorption features occur at temperatures that correspond well with our assignments for ethanol adsorbed on terrace $\mathrm{Au}\left(T_{\text {des }}=175 \mathrm{~K}\right)$, step edges $\left(T_{\text {des }}=195 \mathrm{~K}\right)$, kink sites $\left(T_{\text {des }}=217 \mathrm{~K}\right)$, and a new peak $\left(T_{d e s}=265 \mathrm{~K}\right)$ corresponding to $\mathrm{TiO}_{2}$ (Figure $\left.\mathrm{S} 4\right)$. (2) The presence of $\mathrm{TiO}_{2}$ nanoparticles potentially disrupts the ordered packing of ethanol on the exposed $\mathrm{Au}(111)$ surface. Previous work with methanol on $\mathrm{Au}(111)$ showed that $\mathrm{H}$-bonding significantly 
influenced the packing structure of methanol on the surface. ${ }^{35}$ The presence of $\mathrm{TiO}_{2}$

nanoparticles on the surface causes the dissociative adsorption of ethanol, which could disrupt $\mathrm{H}$ bonding between ethanol molecules on the surface and allow for the enhanced total adsorption of ethanol by tightly packing ethanol on the surface. Furthermore, the stronger adsorption energy between $\mathrm{TiO}_{2}$ and ethanol could influence the density of the molecules on the nanoparticles, as compared to on the Au surface, where the H-bonded networks ${ }^{35}$ will dominate the packing density.

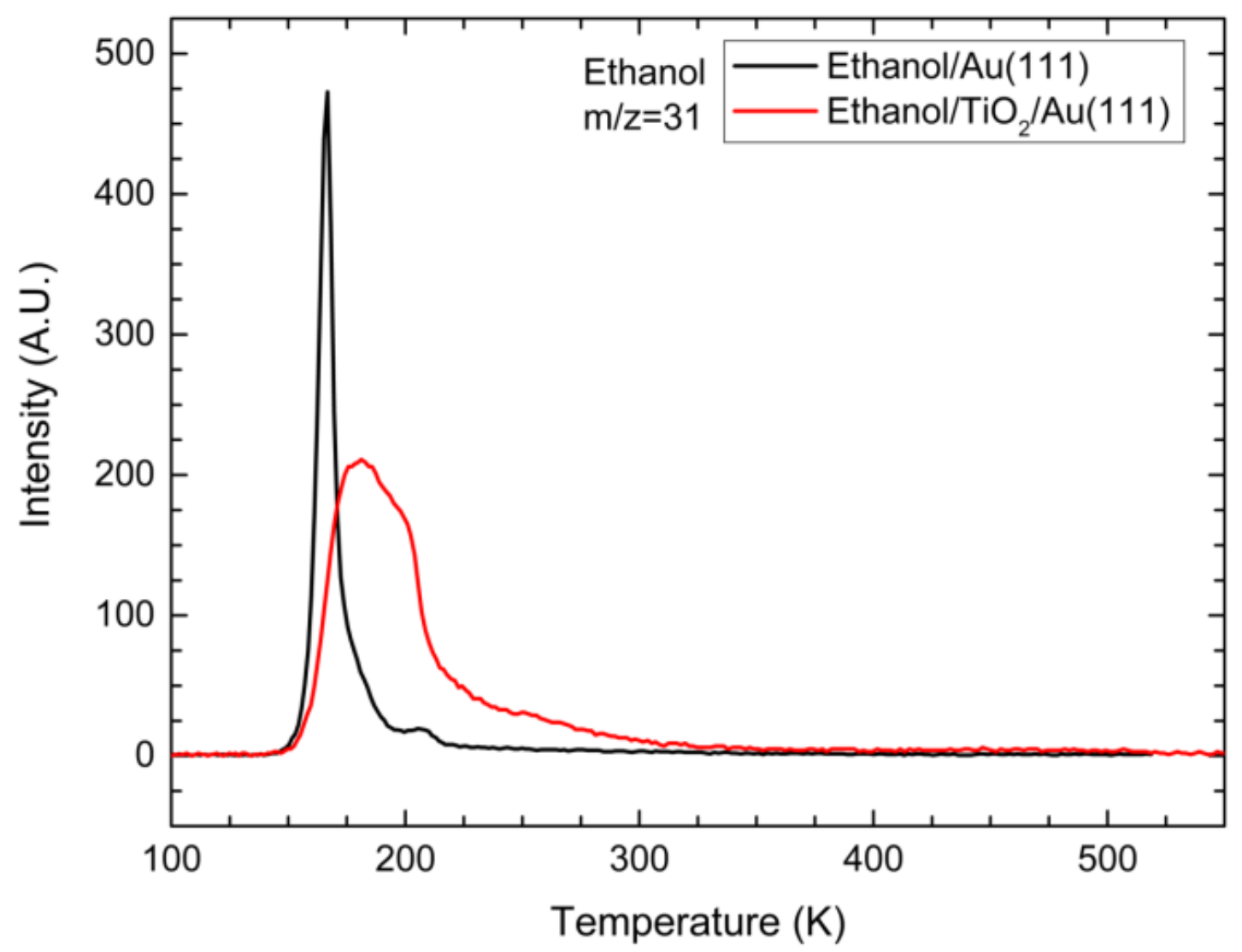

Figure 7. TPD spectra of ethanol desorption from clean $\mathrm{Au}(111)$ (black line) and nanoparticle $\mathrm{TiO}_{2} / \mathrm{Au}(111)$ (red line). The increased area under the red curve suggests an increase in the distribution of adsorption sites as well as the concentration of surface-bound molecules. 
Temperature-programmed reaction spectroscopy (TPRS) experiments of ethanol/ $\mathrm{TiO}_{2} / \mathrm{Au}(111)$ show that the nanoparticle $\mathrm{TiO}_{2} / \mathrm{Au}(111)$ surface is active for the transformation of ethanol into both ethylene and acetaldehyde (Figure 8). Previous work with methanol and 2-propanol demonstrated that both alcohols underwent redox chemistry that depended on the specific method of surface preparation and the oxidation state of $\mathrm{TiO}_{2} \cdot{ }^{21,22} \mathrm{The}$ preparation of the $\mathrm{Au}(111)$ supported $\mathrm{TiO}_{2}$ nanoparticles was consistent for the TPRS experiments described herein. Prior to TPRS experiments, the $\mathrm{TiO}_{2} / \mathrm{Au}(111)$ surface was oxidized at $600 \mathrm{~K}$ with an $\mathrm{O}_{2}$ background of $2 \times 10^{-7}$ torr. Several m/z ratios were monitored during experiments to elucidate different products, as several $\mathrm{m} / \mathrm{z}$ ratios for potential reaction products overlap. The main species monitored were ethanol $(\mathrm{m} / \mathrm{z}=31,46,45)$, ethylene, $(\mathrm{m} / \mathrm{z}=28$, 27, 26), and acetaldehyde $(\mathrm{m} / \mathrm{z}=29,44,43)$. Coupling products as well as smaller molecules resulting from the cleavage of $\mathrm{C}-\mathrm{C}$ bonds were not detected. Six representative $\mathrm{m} / \mathrm{z}$ ratios are shown to represent ethanol $(\mathrm{m} / \mathrm{z}=46)$, acetaldehyde $(\mathrm{m} / \mathrm{z}=29,43,44)$, ethylene $(\mathrm{m} / \mathrm{z}=27)$, and water $(\mathrm{m} / \mathrm{z}=18)$. The left panel displays the full temperature range of the TPR spectrum, which expectedly shows the desorption of ethanol over the lower temperature range between 170 and $250 \mathrm{~K}$. 


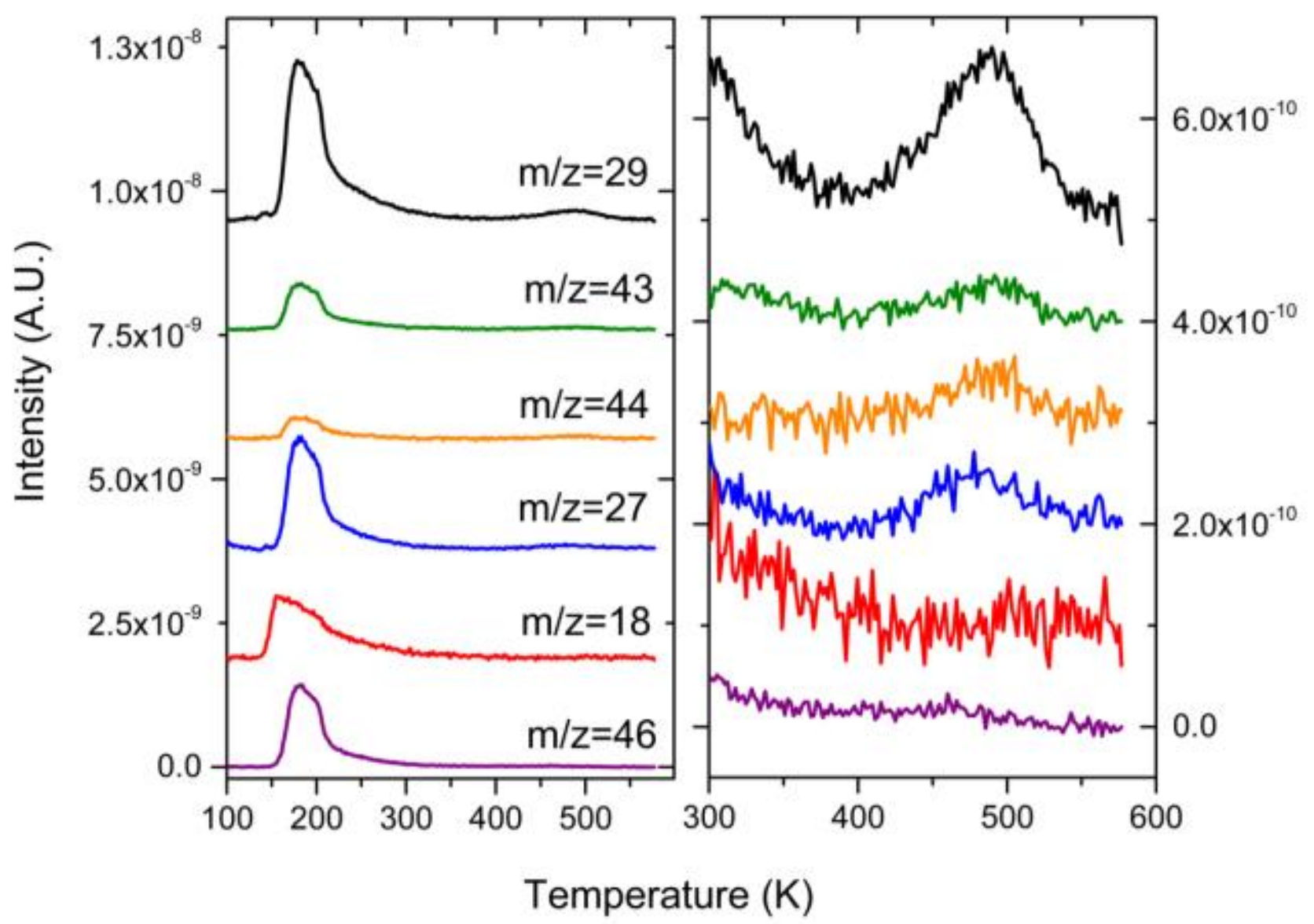

Figure 8. TPR spectrum shows the ethanol-derived products formed over $\mathrm{TiO}_{2}$ nanoparticles supported on $\mathrm{Au}(111)$. The left panel shows low-temperature ethanol desorption, and the right panel highlights the product formation at $T_{\text {des }}=\sim 500 \mathrm{~K}$.

The right panel highlights the high-temperature component of the TPR spectrum. This data indicates the formation of acetaldehyde $(\mathrm{m} / \mathrm{z}=29,44,43)$, ethylene $(\mathrm{m} / \mathrm{z}=27)$, and water $(\mathrm{m} / \mathrm{z}=18)$ from ethanol $(\mathrm{m} / \mathrm{z}=46)$ over the $\mathrm{TiO}_{2} / \mathrm{Au}(111)$ surface. While $\mathrm{m} / \mathrm{z}=29$ corresponds to both ethanol and acetaldehyde, the combination of high $T_{\text {des }}$ peaks for $\mathrm{m} / \mathrm{z}=29,44,43$ with the lack of a high $T_{\text {des }}$ peak for $\mathrm{m} / \mathrm{z}=46$ shows that the desorption features are not the result of ethanol fragmentation but rather that acetaldehyde is in fact a high $T_{\text {des }}$ product. Similarly, a m/z ratio of 27 is observed for both ethanol and ethylene, but the lack of high-temperature desorption 
of $\mathrm{m} / \mathrm{z}=46$ indicates that the desorption of $\mathrm{m} / \mathrm{z}=27$ corresponds to ethylene. The desorption temperatures of acetaldehyde and ethylene are significantly lower on the $\mathrm{TiO}_{2} / \mathrm{Au}(111)$ surface $\left(T_{d e s}=\sim 500 \mathrm{~K}\right)$ as compared to those on the $\mathrm{TiO}_{2}(110)$ surface $\left(T_{d e s}=\sim 620 \mathrm{~K}\right)^{20}$. Sequential ethanol TPR experiments did not result in a change in a distribution in the ethanol-derived products, i.e., after multiple experiments the ratio between oxidized (acetaldehyde) and reduced (ethylene) products did not change, indicating that there was not a significant oxidation or reduction of the surface due to ethanol reaction. We hypothesize that ethanol deprotonates at the interface to form ethoxy and adsorbed $\mathrm{H}$ at low temperatures. Future work will extend to isotopic studies, as well as altering coverages and surface preparations of $\mathrm{TiO}_{2}$ to discern the effect of $\mathrm{TiO}_{2}$ nanoparticle size and surface condition on the reaction pathway for the reaction of ethanol. 


\section{Conclusions}

The desorption of ethanol from multilayers, Au terraces, Au step edges, and Au kink sites were differentiated via coverage-dependent TPD studies. Upon the deposition of $\mathrm{TiO}_{2}$

nanoparticles on $\mathrm{Au}(111)$, a broadening of the low-temperature ethanol desorption peak is observed with a maximum desorption temperature of $T_{d e s}=\sim 235 \mathrm{~K}$. The desorption of ethanol from $\mathrm{TiO}_{2} / \mathrm{Au}(111)$ occurs at an intermediate temperature between bulk $\mathrm{Au}(111)$ and $\mathrm{TiO}_{2}(110)$. This intermediate desorption temperature indicates that ethanol dissociatively adsorbs into ethoxy and adsorbed hydrogen at the interface between $\mathrm{TiO}_{2}$ nanoparticles and $\mathrm{Au}(111)$ prior to forming acetaldehyde or ethylene. 


\section{Supporting Information/Appendix}

Ex situ AFM images show the morphology of the clean (left panel) and roughened (right panel) $\mathrm{Au}(111)$ surface. The roughened AFM image has roughly 50 kinks in the $1000 \mathrm{~nm}$ square image on the right. While this is not a true count of the total number of kinks in the surface, the shape of the edges allows for the rough estimation of the low end number of kinks per area.
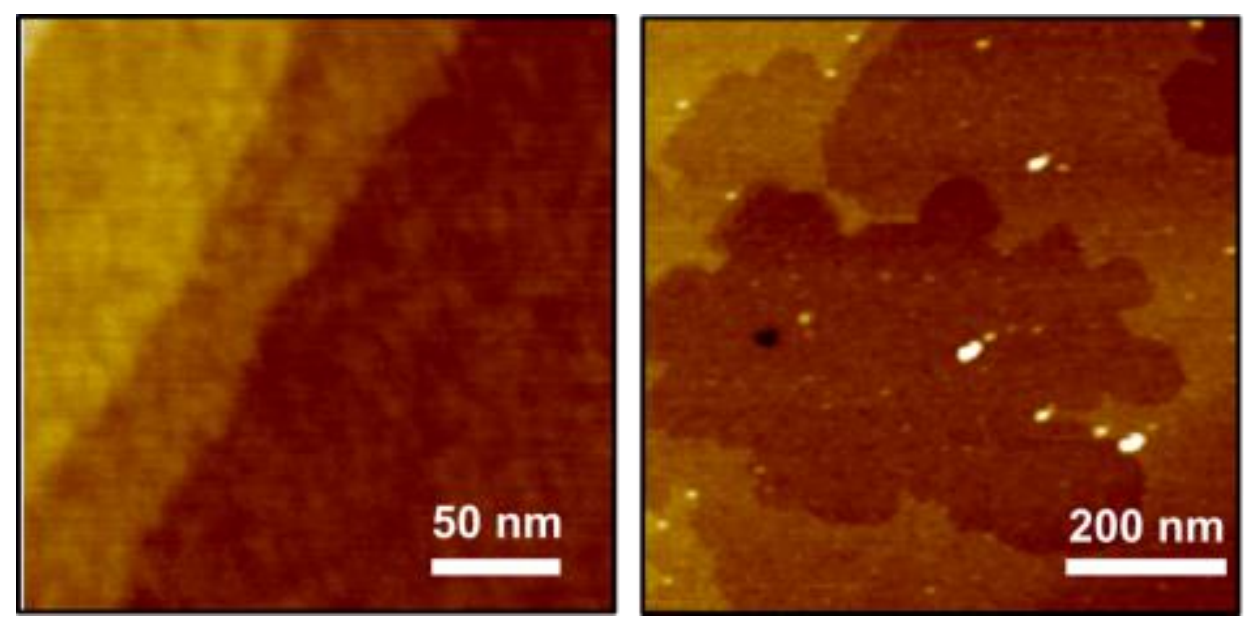

Figure S1. Ex situ AFM images of $\mathrm{Au}(111)$ (left) and roughened $\mathrm{Au}(111)$ (right). The roughened $\mathrm{Au}(111)$ was sputtered and annealed to $600 \mathrm{~K}$. 


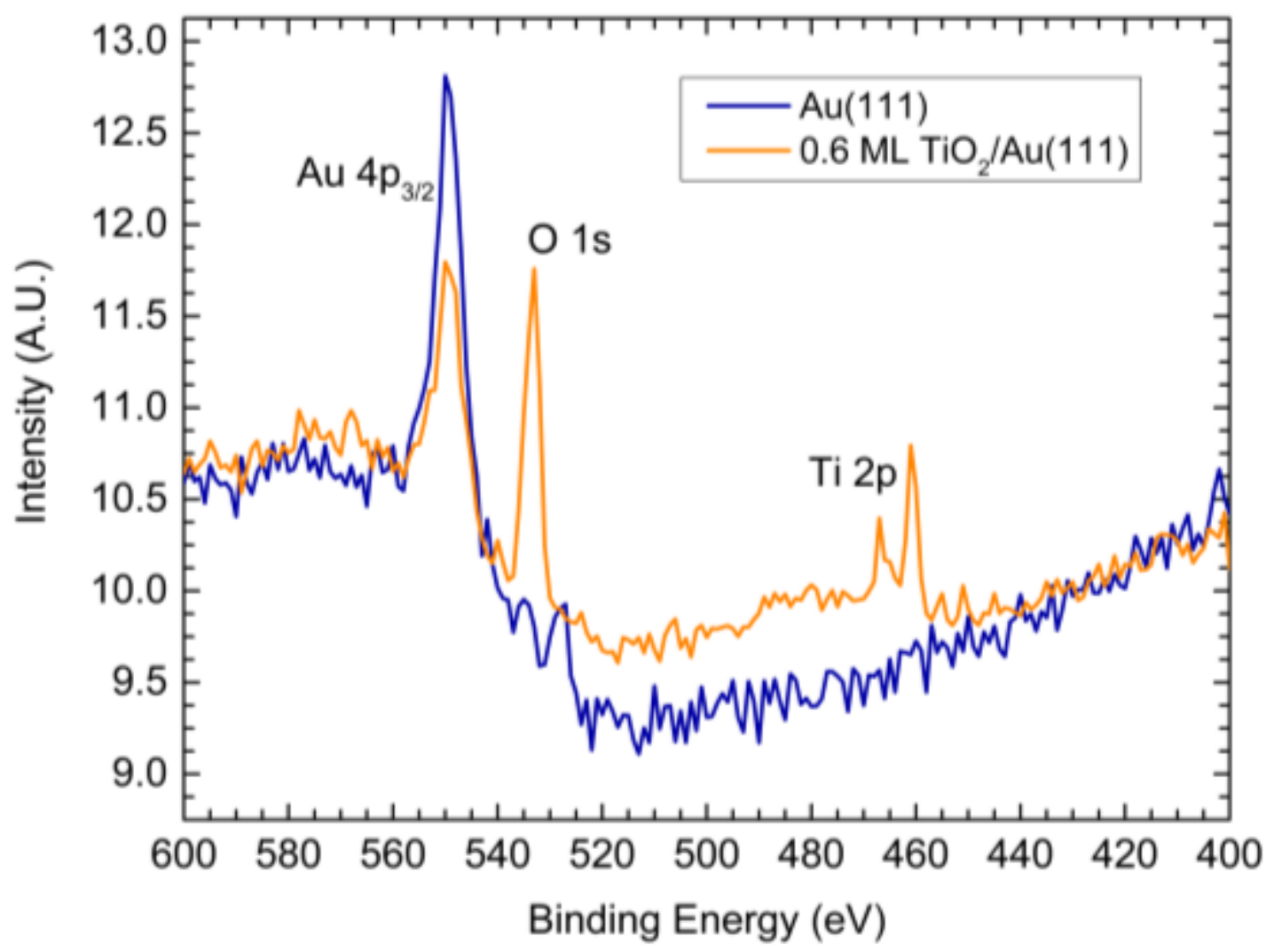

Figure S2. Ex situ XPS: Clean $\mathrm{Au}(111)$ (Blue) and 0.6 ML TiO2/Au(111) (Orange). 


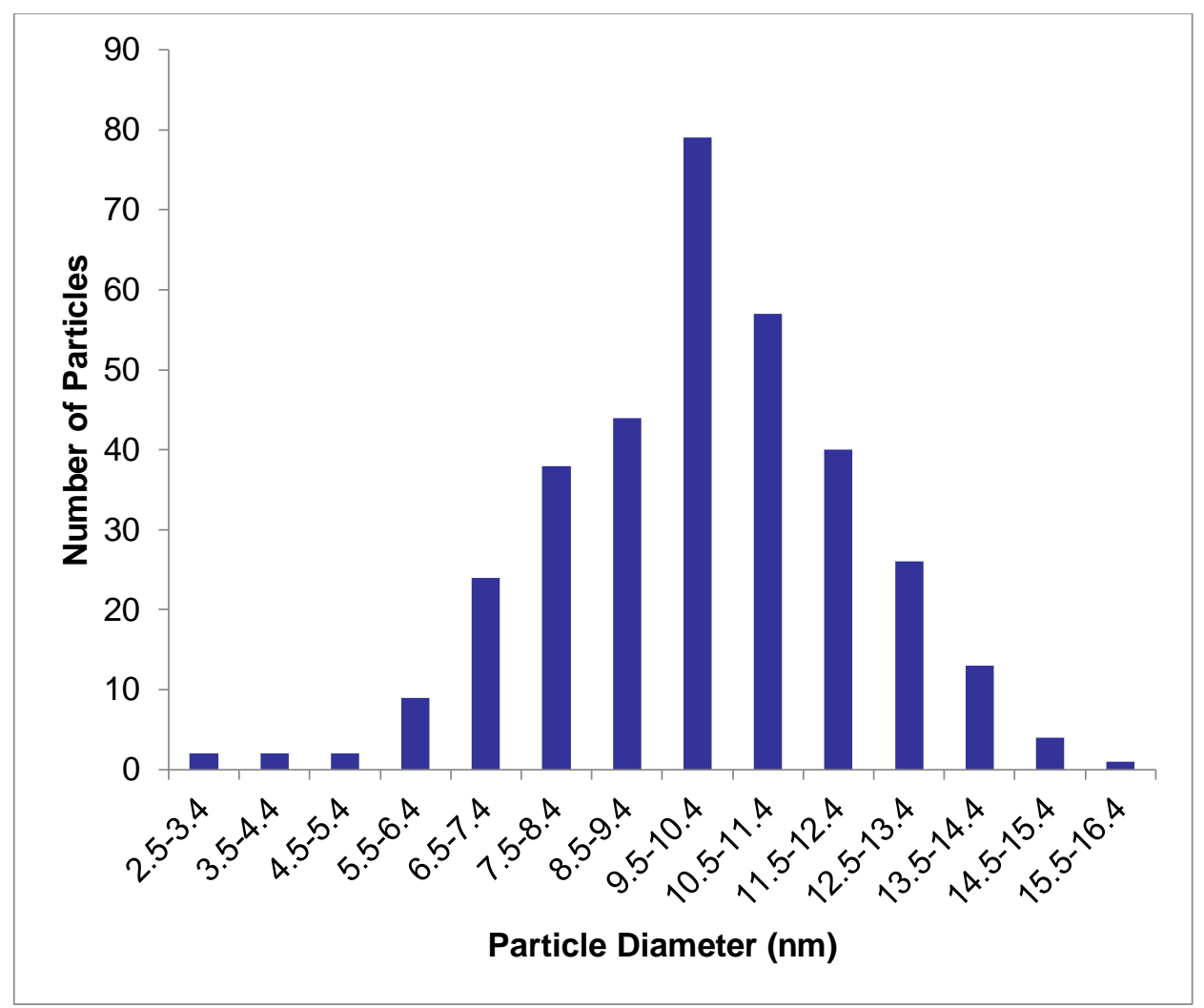

Figure S3. Ex situ AFM Analysis: Histogram of particle diameters for nanoparticle $\mathrm{TiO}_{2}$ coverage (0.6 ML) on a $\mathrm{Au}(111)$ surface. The average diameter of the $\mathrm{TiO}_{2}$ nanoparticles is 10.1 $\pm 2.2 \mathrm{~nm}$. 
Peak analysis indicates that the broad low $T_{\mathrm{des}}$ is the result of several desorption peaks for ethanol, which make up the overall peak (Figure 7). The formation of several new peaks for ethanol with a higher $T_{\text {des }}$ indicates that $\mathrm{TiO}_{2}$ forms new adsorption sites with higher binding energies to ethanol. Analysis of the underlying peaks shows that a portion of the broad low temperature peak is made up of ethanol desorption from the $\mathrm{Au}(111)$ terrace $(175 \mathrm{~K})$, Au step edges (195 K), Au kink sites (217 K) and $\mathrm{TiO}_{2}$ nanoparticle sites (265 K) (Figure S4).

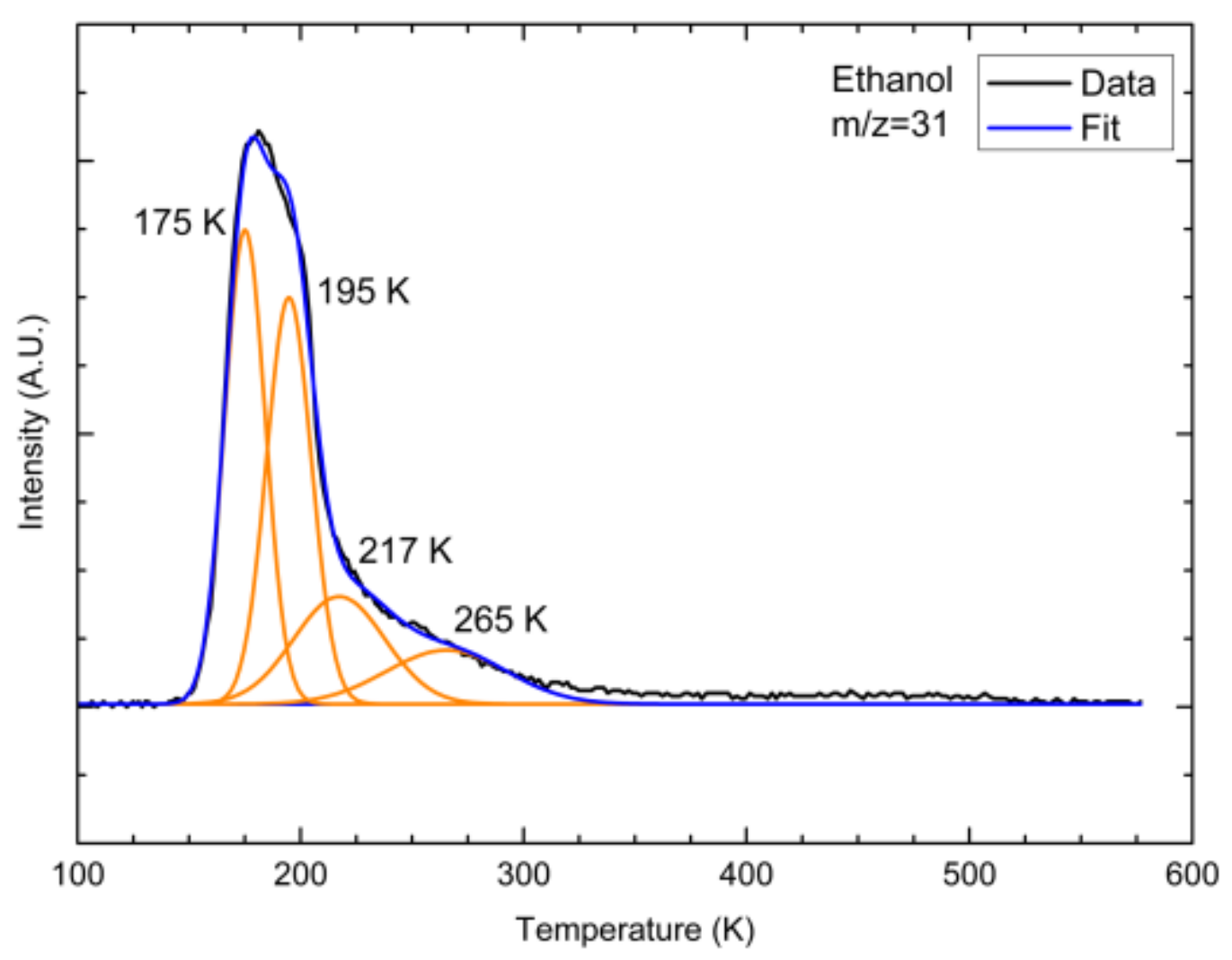

Figure S4. Peak fitting of ethanol desorption from $\sim 0.3 \mathrm{ML} \mathrm{TiO}_{2} / \mathrm{Au}(111)$. The peaks correspond to ethanol adsorbed to the $\mathrm{Au}(111)$ terrace (175 K), Au step edges (195 K), Au kink site $(217 \mathrm{~K})$, and $\mathrm{TiO}_{2}$ site $(265 \mathrm{~K})$. 


\section{References}

(1) Panayotov, D. A.; Morris, J. R. Surface Chemistry of $\mathrm{Au} / \mathrm{TiO}_{2}$ : Thermally and Photolytically Activated Reactions. Surf. Sci. Rep. 2016, 71, 77-271.

(2) Tao, F.; Ma, Z. Water-gas Shift on Gold Catalysts: Catalyst Systems and Fundamental Studies. Phys. Chem. Chem. Phys 2013, 15, 15260-15270.

(3) Rodriguez, J. A.; Ma, S.; Liu, P.; Hrbek, J.; Evans, J.; Pérez, M. Activity of CeOx and TiOx Nanoparticles Grown on Au(111) in the Water-Gas Shift Reaction. Science 2007, $318,1757-1760$.

(4) Green, I. X.; Tang, W.; Neurock, M.; Yates, J. T. Insights into Catalytic Oxidation at the $\mathrm{Au} / \mathrm{TiO}_{2}$ Dual Perimeter Sites. Acc. Chem. Res. 2014, 47, 805-815.

(5) Nadeem, A. M.; Idriss, H.; Zealand, N. Hydrogen Photo-Production from Ethanol on $\mathrm{TiO}_{2}$ : A Surface Science and Catalysis. Proc. SPIE - Int. Soc. Opt. Eng. 2011, 8109, 81090K.

(6) Nadeem, M. A.; Murdoch, M.; Waterhouse, G. I. N.; Metson, J. B.; Keane, M. A.; Llorca, J.; Idriss, H. Photoreaction of Ethanol on $\mathrm{Au} / \mathrm{TiO}_{2}$ Anatase: Comparing the Micro to Nanoparticle Size Activities of the Support for Hydrogen Production. J. Photochem. Photobiol. A Chem. 2010, 216, 250-255.

(7) Murdoch, M.; Waterhouse, G. I. N.; Nadeem, M. A.; Metson, J. B.; Keane, M. A.; Howe, R. F.; Llorca, J.; Idriss, H. The Effect of Gold Loading and Particle Size on Photocatalytic Hydrogen Production from Ethanol over Au/TiO2 Nanoparticles. Nat. Chem. 2011, 3, 489-492.

(8) Nadeem, A. M.; Waterhouse, G. I. N.; Idriss, H. The Reactions of Ethanol on $\mathrm{TiO}_{2}$ and $\mathrm{Au} / \mathrm{TiO}_{2}$ Anatase Catalysts. Catal. Today 2012, 182, 16-24.

(9) Grunwaldt, J.-D.; Baiker, A. Gold/Titania Interfaces and Their Role in Carbon Monoxide 
Oxidation. J. Phys. Chem. B 1999, 103, 1002-1012.

(10) Saavedra, J.; Doan, H. A.; Pursell, C. J.; Grabow, L. C.; Chandler, B. D. The Critical Role of Water at the Gold-Titania Interface in Catalytic CO Oxidation. Science 2014, 345, 1599-1602.

(11) Liu, Z.-P.; Gong, X.-Q.; Kohanoff, J.; Sanchez, C.; Hu, P. Catalytic Role of Metal Oxides in Gold-Based Catalysts: A First Principles Study of CO Oxidation on $\mathrm{TiO}_{2}$ Supported Au. Phys. Rev. Lett. 2003, 91, 266102.

(12) Farnesi Camellone, M.; Marx, D. Nature and Role of Activated Molecular Oxygen Species at the Gold/Titania Interface in the Selective Oxidation of Alcohols. J. Phys. Chem. C 2014, 118, 20989-21000.

(13) Nakamura, I.; Mantoku, H.; Furukawa, T.; Fujitani, T. Active Sites for Hydrogen Dissociation over TiOx/Au(111) Surfaces. J. Phys. Chem. C 2011, 115, 16074-16080.

(14) Christensen, C. H.; Jørgensen, B.; Rass-Hansen, J.; Egeblad, K.; Madsen, R.; Klitgaard, S. K.; Hansen, S. M.; Hansen, M. R.; Andersen, H. C.; Riisager, A. Formation of Acetic Acid by Aqueous-Phase Oxidation of Ethanol with Air in the Presence of a Heterogeneous Gold Catalyst. Angew. Chemie - Int. Ed. 2006, 45, 4648-4651.

(15) Gong, J.; Mullins, C. Selective Oxidation of Ethanol to Acetaldehyde on Gold. J. Am. Chem. Soc. 2008, 130, 16458-16459.

(16) Liu, X.; Xu, B.; Haubrich, J.; Madix, R. J.; Friend, C. M. Surface-Mediated Self-Coupling of Ethanol on Gold. J. Am. Chem. Soc. 2009, 131, 5757-5759.

(17) Jayaweera, P. M.; Quah, E. L.; Idriss, H. Photoreaction of Ethanol on $\mathrm{TiO}_{2}(110)$ SingleCrystal Surface. J. Phys. Chem. C 2007, 111, 1764-1769.

(18) Kim, Y. K.; Kay, B. D.; White, J. M.; Dohnálek, Z. Alcohol Chemistry on Rutile 
$\mathrm{TiO}_{2}(110)$ : The Influence of Alkyl Substituents on Reactivity and Selectivity. J. Phys. Chem. C 2007, 111, 18326-18342.

(19) Gamble, L.; Jung, L. S.; Campbell, C. T. Decomposition and Protonation of Surface Ethoxys on $\mathrm{TiO}_{2}(110)$. Surf. Sci. 1996, 348, 1-16.

(20) Farfan-Arribas, E.; Madix, R. J. Role of Defects in the Adsorption of Aliphatic Alcohols on the $\mathrm{TiO}_{2}(110)$ Surface. J. Phys. Chem. B 2002, 106, 10680-10692.

(21) Farfan-Arribas, E.; Biener, J.; Friend, C. M.; Madix, R. J. Reactivity of Methanol on $\mathrm{TiO}_{2}$ Nanoparticles Supported on the Au(111) Surface. Surf. Sci. 2005, 591, 1-12.

(22) Potapenko, D. V.; Li, Z.; Lou, Y.; Guo, Y.; Osgood, R. M. 2-Propanol Reactivity on in Situ Prepared $\mathrm{Au}(111)-$ Supported $\mathrm{TiO}_{2}$ Nanocrystals. J. Catal. 2013, 297, 281-288.

(23) Hrbek, J.; Hoffmann, F. M.; Park, J. B.; Liu, P.; Stacchiola, D.; Hoo, Y. S.; Ma, S.; Nambu, A.; Rodriguez, J. A.; White, M. G. Adsorbate-Driven Morphological Changes of a Gold Surface at Low Temperatures. J. Am. Chem. Soc. 2008, 130, 17272-17273.

(24) Hoffmann, F. M.; Hrbek, J.; Ma, S.; Park, J. B.; Rodriguez, J. A.; Stacchiola, D. J.; Senanayake, S. D. Enhancing the Reactivity of Gold: Nanostructured Au(111) Adsorbs CO. Surf. Sci. 2016, 650, 17-23.

(25) Pászti, Z.; Hakkel, O.; Keszthelyi, T.; Berkó, A.; Balázs, N.; Bakó, I.; Guczi, L. Interaction of Carbon Monoxide with Au(111) Modified by Ion Bombardment: A Surface Spectroscopy Study under Elevated Pressure. Langmuir 2010, 26, 16312-16324.

(26) Pischel, J.; Pucci, A. Low-Temperature Adsorption of Carbon Monoxide on Gold Surfaces: IR Spectroscopy Uncovers Different Adsorption States on Pristine and Rough Au(111). J. Phys. Chem. C 2015, 119, 18340-18351.

(27) Yim, W. L.; Nowitzki, T.; Necke, M.; Schnars, H.; Nickut, P.; Biener, J.; Biener, M. M.; 
Zielasek, V.; Al-Shamery, K.; Klüner, T.; et al. Universal Phenomena of CO Adsorption on Gold Surfaces with Low-Coordinated Sites. J. Phys. Chem. C 2007, 111, 445-451.

(28) Carabineiro, S. A. C.; Nieuwenhuys, B. E. Adsorption of Small Molecules on Gold Single Crystal Surfaces. Gold Bull. 2009, 42, 288-301.

(29) Biener, J.; Biener, M. M.; Nowitzki, T.; Hamza, A. V.; Friend, C. M.; Zielasek, V.; Bäumer, M. On the Role of Oxygen in Stabilizing Low-Coordinated Au Atoms. ChemPhysChem 2006, 7, 1906-1908.

(30) Tereshchuk, P.; Da Silva, J. L. F. Ethanol and Water Adsorption on Close-Packed 3d, 4d, and 5d Transition-Metal Surfaces: A Density Functional Theory Investigation with van Der Waals Correction. J. Phys. Chem. C 2012, 116, 24695-24705.

(31) Gong, J.; Flaherty, D. W.; Ojifinni, R. A.; White, J. M.; Mullins, C. B. Surface Chemistry of Methanol on Clean and Atomic Oxygen Pre-Covered Au(111). J. Phys. Chem. C. 2007, $112,5501-5509$.

(32) Jenniskens, H. G.; Dorlandt, P. W. F.; Kadodwala, M. F.; Kleyn, A. W. The Adsorption of Methanol on $\mathrm{Ag}(111)$ Studied with TDS and XPS. Surf. Sci. 1996, 357-358, 624-628.

(33) Ehlers, D. H.; Spitzer, A.; Luth, H. The Adsorption of Methanol on Pt(111), an IR Reflection and UV Photoemission Study. Surf. Sci. 1985, 160, 57-69.

(34) Burke, D. J.; Wolff, A. J.; Edridge, J. L.; Brown, W. A. The Adsorption and Desorption of Ethanol Ices from a Model Grain Surface. J. Chem. Phys. 2008, 128, 104702.

(35) Baber, A. E.; Lawton, T. J.; Sykes, E. C. H. Hydrogen-Bonded Networks in SurfaceBound Methanol. J. Phys. Chem. C 2011, 115, 9157-9163.

(36) Baber, A. E.; Jensen, S. C.; Iski, E. V.; Sykes, E. C. H. Extraordinary Atomic Mobility of $\mathrm{Au}\{111\}$ at 80 Kelvin: Effect of Styrene Adsorption. J. Am. Chem. Soc. 2006, 128, 
$15384-15385$.

(37) Driver, S. M.; Zhang, T.; King, D. A. Massively Cooperative Adsorbate-Induced Surface Restructuring and Nanocluster Formation. Angew. Chemie - Int. Ed. 2007, 46, 700-703.

(38) Hrbek, J.; Hoffmann, F. M.; Park, J. B.; Liu, P.; Stacchiola, D.; Hoo, Y. S.; Ma, S.;

Nambu, A.; Rodriguez, J. A.; White, M. G. Adsorbate-Driven Morphological Changes of a Gold Surface at Low Temperatures. J. Am. Chem. Soc. 2008, 130, 17272-17273.

(39) Mullins, D. R.; Senanayake, S. D.; Chen, T. L. Adsorption and Reaction of C1-C3 Alcohols over CeOx(111) Thin Films. J. Phys. Chem. C 2010, 114, 17112-17119.

(40) Liu, Z.; Duchon, T.; Wang, H.; Grinter, D. C.; Waluyo, I.; Zhou, J.; Liu, Q.; Jeong, B.;

Crumlin, E. J.; Matolin, V.; et al. Ambient Pressure XPS and IRRAS Investigation of Ethanol Steam Reforming on $\mathrm{Ni}_{-} \mathrm{CeO}_{2}(111)$ Catalysts: An in Situ Study of C-C and O-H Bond Scission. Phys. Chem. Chem. Phys. 2016, 18, 16621-16628.

(41) Senanayake, S. D.; Mudiyanselage, K.; Bruix, A.; Agnoli, S.; Hrbek, J.; Stacchiola, D.; Rodriguez, J. A. The Unique Properties of the Oxide-Metal Interface: Reaction of Ethanol on an Inverse Model CeOx-Au(111) Catalyst. J. Phys. Chem. C 2014, 118, 25057-25064.

(42) Ragazzon, D.; Schaefer, A.; Farstad, M. H.; Walle, L. E.; Palmgren, P.; Borg, A.; Uvdal, P.; Sandell, A. Chemical Vapor Deposition of Ordered TiOx Nanostructures on Au(111). Surf. Sci. 2013, 617, 211-217.

(43) Song, Z.; Hrbek, J.; Osgood, R. Formation of $\mathrm{TiO}_{2}$ Nanoparticles by Reactive-LayerAssisted Deposition and Characterization by XPS and STM. Nano Lett. 2005, 5, 13271332.

(44) Ragazzon, D.; Farstad, M. H.; Schaefer, A.; Walle, L. E.; Uvdal, P.; Borg, A.; Sandell, A. Growth of $\mathrm{TiO}_{2}(\mathrm{~B})(001)$ on $\mathrm{Au}(111)$ by Chemical Vapor Deposition. Surf. Sci. 2015, 633, 
$102-108$.

(45) Biener, J.; Farfan-Arribas, E.; Biener, M.; Friend, C. M.; Madix, R. J. Synthesis of TiO 2 Nanoparticles on the Au(111) Surface. J. Chem. Phys. 2005, 123, 0947051-0947056.

(46) Potapenko, D. V; Osgood, R. M. Preparation of $\mathrm{TiO}_{2}$ Nanocrystallites by Oxidation of TiAu (111) Surface Alloy. Nano Lett. 2009, 9, 2378-2383.

(47) Kim, Y. K.; Kay, B. D.; White, J. M.; Dohnálek, Z. Inductive Effect of Alkyl Chains on Alcohol Dehydration at Bridge-Bonded Oxygen Vacancies of $\mathrm{TiO}_{2}(110)$. Catal. Letters 2007, 119, 1-4. 